\title{
THE DETERMINANTS OF INAPPROPRIATE USE OF ANTIBIOTICS AMONG WORKING AGE POPULATION IN WESTERN CAMBODIA
}

\author{
Dimol Sok, Wongsa Lohasiriwong, \\ Somsak Pitaksanurat, Teerasak Phajan \\ Faculty of Public Health, KhonKaen University, Thailand \\ Board Committee of Research and Training Center for Enhancing \\ Quality of Life of Working Age People, KhonKaen University, Thailand
}

\begin{abstract}
BACKGROUND: Antibiotics are among the most commonly sold drugs in the developing countries. The inappropriate use of antibiotics could result not only resistant bacterial strains but also adverse reactions and economic burden. This study aimed to describe the antibiotics use characteristics and identify factors associated with inappropriate use of antibiotics among working age population in western Cambodia.

SUBJECT AND METHODS: This was a cross sectional study. A sample of 344 subjects aged 18-59 years old was selected at random from 10 communes of three provinces in Western Cambodia. A structured questionnaire was developed to collect the data. The dependent variable was inappropriate use of antibiotics. The independent variable included average monthly family income, habitual use of medicine. A logistic regression was used to analyze the data.

RESULTS: $23.84 \%$ of the sample used antibiotic during the past 3 months, of which $14.83 \%$ were inappropriate use. The multivariate analysis indicated factor associated with inappropriate use of antibiotics were: low family income (adj. OR $=3.39 ; 95 \%$ CI: 1.18 to $9.74 ; \mathrm{p}=0.024$ ) and habitual use of oral antibiotics when having a cold (adj. OR=6.44; 95\% CI: 1.55 to $26.91 ; \mathrm{p}=0.010)$. The protective factor was habit of using oral antibiotics when having sorethroat (adj. OR=0.24; 95\%CI: 0.08 to 0.78 ; $\mathrm{p}=0.018$ ).

CONCLUSION: Almost a quarter of the samples used antibiotics. Low income and inappropriate antibiotic administration in respiratory tract infection increase the risk of antibiotic misuse.
\end{abstract}

Keywords: inappropriate use, antibiotics, income, habit, working age population. 